\title{
THE ANALYSIS OF PHYSICO-CHEMICAL PROPERTIES OF TWO UNKNOWN FILTER MATERIALS
}

\author{
Iwona Skoczko' , Ewa Szatyłowicz' \\ 1 Department of Technology in Environmental Engineering and Protection, Faculty of Civil and Environmental \\ Engineering, Białystok University of Technology, Wiejska 45E Str., 15-351 Białystok, Poland, e-mail: \\ i.skoczko@pb.edu.pl, e.szatylowicz@doktoranci.pb.edu.pl
}

Received: 2016.03.16

Accepted: 2016.06.01 Published: 2016.07.01

\begin{abstract}
One of the most important technological processes of water treatment is the process of filtration. Scientists and producers keep on searching new filtration materials which allow for better water purification, are simple in exploitation and do not add chemical substances to the treated water. Therefore, the aim of the present study was to analyze physical and chemical parameters of two unknown porous masses X1 and $\mathrm{X} 2$. Such physical parameters as color, granulation, bulk density, the equivalent diameter, the coefficient of uniformity and the porosity of the material were measured and determined. Additionally, the possibility of water treatment was studied during the filtration process in the laboratory tests. Chemical parameters were examined in the water flowing through the mass, such as $\mathrm{pH}$, conductivity and COD-Mn as a general indicator of the content of organic substances in the water. Both studied porous masses were characterized by uniform size of particles. But they were not efficient enough in satisfactory reduction of oxygen consumption. Mass X2 slightly better adsorbed organic substances. It was found that the tested unknown mass filter slightly increase the $\mathrm{pH}$ of the filtered water.
\end{abstract}

Keywords: porous materials, water purification, properties of filtration materials

\section{INTRODUCTION}

The new trend of water technology goes to replacement of chemical processes with physical processes. Global water sources are polluted with a lot of chemical substances from industrial production, farming and ordinary human being. Some of them are removed during water treatment. Others are added in the same time realizing chemical purification [Skoczko et al. 2015]. Filtration is one of the most popular technological processes. It is easy to use in most of the Water Treatment Plants (WTP). There are various types of columns and materials which may be used. Filtration efficiency depends on the process which is carried out in a particular filter. In addition, properly selected and applied filling of the column might reduce the total space of the treatment plant and achieve measurable economic effect as mini- mizing capital expenditures and operating costs [Skoczko, Kisło 2014]. Filters have several particular features as resistance to chemical agents (such as acids and bases), mechanical integrity, and should not add any toxic substances to water [Nawrocki 2010].

Different filter materials can be used as a filling of the column. They may be natural or have synthetic origin. Natural filter materials might include: silica sand, grit marble, crushed granite, diatomite, anthracite, zeolite, pyrolusite. There are also masses of natural origin that were created as a result of tooling with heat or chemicals. These include activated carbon, expanded clay, coke, expanded clay crushed, calcined dolomite or volcanic pumice [Nawrocki 2010, Çeçen, Aktaş 2011]. The synthetic filter materials are derived from plastic [Nawrocki 2010; Weber, JeżWalkowiak 2006, Kaleta et al. 2009]. Each mass 
might be used as a layer in a multifilter or as separated column in water treatment system.

The parameters that determine the properties of the filter material are [Kowal 2009; JeżWalkowiak 2013]:

- diameter grains,

- porosity.

- bulk density,

- mechanical strength,

- chemical composition,

- grain shape,

- purity - that is lack of leaching potential contaminants and pathogenic microorganism.

The shape and size of the grains determine the geometry of the filtration bed and its hydraulic features as well as their mutual arrangement. The suitability of a filter material for filtration process taking into consideration the active diameter $\left(\mathrm{d}_{10}\right)$ and the coefficient of uniformity (WR) $\mathrm{d}_{60} / \mathrm{d}_{10}$ are assessed. According to Kowal, active diameter of filter bed is such a diameter that is less than $10 \%$ of total material sample weight together with smaller grains and it is the median of all the grains of the filter bed. On the other hand, $d_{60}$ is such a diameter which, together with smaller grains includes $60 \%$ of total sample weight of filter material [Nawrocki, Biłozor 2000, Kowal 2009].

Scientists and producers keep on searching new filtration materials which allow for better water purification, are simple in exploitation and do not add chemical substances to the treated water. Filter masses should be ecological, effective and inexpensive. Therefore, two unknown natural porous materials were considered, analyzed and evaluated for use as filter beds.

\section{MATERIAL AND METHODS}

The study was carried out in the laboratory of the Department of Technology in Environmental Engineering and Protection at Bialystok University of Technology. The aim of study was to analyze the physical and chemical parameters of two unknown porous masses X1 and X2. Physical parameters such as color, granulation, bulk density, equivalent diameter, coefficient of uniformity and porosity of the material were measured and determined. Additionally, the possibility of water treatment was studied during the filtration process in laboratory tests. Chemical parameters were examined in the water flowing through the mass, such as $\mathrm{pH}$, conductivity and COD-Mn as a general indicator of the content of organic substances in the water. The tested model consisted of two separatory funnels that were filled with filtration masses called as $\mathrm{X} 1$ and $\mathrm{X} 2$ of unknown origin and properties. Figure 1 present studied material used for filtration. The volume of the separatory funnels was $1 \mathrm{dm}^{3}$ height -24 $\mathrm{cm}$, diameter $-12 \mathrm{~cm}$. The contaminated water was pumped with rubber pipes with a diameter of $\varphi 3 \mathrm{~mm}$ by a peristaltic pump type PP1B - 05A companies ZALIMP into filter columns from the barrel with a capacity of $120 \mathrm{dm}^{3}$. Water quantity was $20 \mathrm{~cm}^{3} / \mathrm{min}$. Each of the studied deposits was flushed with tap water before the proper filtration process. The time of filters flushing lasted 7 days continuously. Water tests were carried out for a period of five weeks until the exhaustion of the bed. Masses worked continuously, 24 hours a day, 7 days a week. Table 1 shows technical operating parameters of filtration masses $\mathrm{X} 1$ and $\mathrm{X} 2$.

Calculations of physical parameters were provided for both filtration materials for accurate characterization of the filter. Due to the fact that the used filter materials were not homogeneous, additional calculations determining the grain diameter were realized. Scientists recommend to perform the sieve analysis in this case. It involves the separation of aggregates fraction using properly dimensioned mesh sieves. A sieve mesh size: $10 \mathrm{~mm}, 6.3 \mathrm{~mm}, 5 \mathrm{~mm}, 2 \mathrm{~mm}$ and $1 \mathrm{~mm}$ were used in the study. Percentage of each fraction of the mass should be fixed after the sieving of the filter material with the formula (1) [Nawrocki, Biłozor 2000, Kowal 2009]:

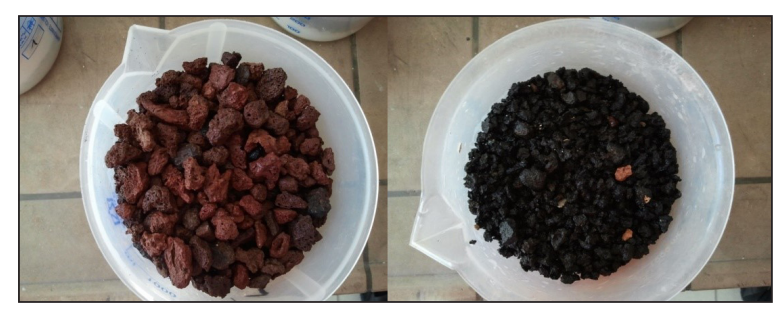

Figure 1. X1 bed on the left side, and on the right side $\mathrm{X} 2$

Table 1. Technical parameters of analyzed filter masses

\begin{tabular}{|l|c|}
\hline Hydraulic load & $0.21 \mathrm{~m}^{3} / \mathrm{m}^{2} \cdot \mathrm{h}$ \\
\hline Temperature & $21-24{ }^{\circ} \mathrm{C}$ \\
\hline Solution flow rate during filtration & $1.2 \mathrm{dm}^{3} / \mathrm{h}$ \\
\hline The volume of the filtration column & $0.9 \mathrm{dm}^{3}$ \\
\hline Filtration surface & $7.75 \mathrm{~cm}^{2}$ \\
\hline
\end{tabular}




$$
a_{i}=\frac{m_{i}}{m_{s}} \cdot 100[\%]
$$

where: $a_{i}-$ the percentage of factions " $i$ " [\%], $m_{i}$ - mass of fraction retained on a sieve "i" [g],

$m_{s}$ - the mass of the whole analyzed sample $[\mathrm{g}]$.

The total sifting was calculated based on the results of sieve analysis corresponding to a particular sieve mesh and summarizing the percentages of the total sieves fraction [Nawrocki, Biłozor 2000, Kowal 2009].

$$
b_{n}=a_{1}+a_{2}+\ldots+a_{n-1}
$$

The results may be shown graphically as a curve of the sieving percentage which depends on the sieve mesh size. The resulting graph helps to read:

- $d_{10}$ - the sieve mesh of $10 \%$ of the filter material weight $[\mathrm{m}]$,

- $d_{60}$ - the sieve mesh of $60 \%$ of the filter material weight [m],

- $d_{\min }-$ the diameter of the smallest particle in the filter bed $[\mathrm{m}]$,

- $d_{\max }$ - the diameter of the largest grain in the filter bed[m].

The equivalent diameter of the material was calculated using such parameters as by the formula [Nawrocki, Biłozor 2000, Kowal 2009]:

$$
d_{r}=\frac{100}{\sum \frac{a_{i}}{d_{i}}}
$$

where: $d_{i}-$ the diameter of the fraction " $i$ " calculated as the arithmetic average of the mesh size, which allows to stop this fraction on the sieve [m],

Another calculated parameter determines the suitability of the filter material. It is the uniformity coefficient WR and it shall be referred to the equation:

$$
W R=\frac{d_{60}}{d_{10}}
$$

A very important element of filtration material is its porosity. Porosity determines the capacity of the bed in which the pollution particles are retained in the solid phase during the filtration process [Kowal, 2009]. There is a relationship which states that the greater the porosity of the material the more particles are retained in the bed and extends the filtration cycle. This parameter is counted in two ways. The first method involves the determination of an approximate porosity of the bed. The cylinder is filled with a predetermined amount of water, then it is filled with preweighed amount of the filter material. The next step is to read the water level, which rises over the material. The volume of the filter bed in the cylinder is also the part of calculation. The read data are substituted into the formula:

$$
\varepsilon=\left(1-\frac{\Delta V_{w}}{V_{m}}\right) \cdot 100[\%]
$$

where: $\Delta V_{w}$ - the volume of water displaced by the filter material $\left[\mathrm{dm}^{3}\right]$,

$V_{m}$ - volume of filter material in the cylin$\operatorname{der}\left[\mathrm{dm}^{3}\right]$.

The second method consists in determining the ratio of the volume of empty spaces between particles of the bed to its total volume. The main step was the crush tested filtration materials to determine the spaces between particles. Then, the porosity of the bed was calculated with the formula [Nawrocki, Biłozor 2000, Kowal 2009]:

$$
\varepsilon=\frac{V_{\text {emty space }}}{V_{\text {total }}}
$$

where: $\varepsilon$-porosity of the bed,

$$
\begin{aligned}
& V_{\text {empty space }}-\text { empty spaces in the bed, } \\
& V_{\text {total }}-\text { total volume of the bed. }
\end{aligned}
$$

$\mathrm{pH}$, conductivity, and concentration of COD$\mathrm{Mn}$ in the water before filtration and after filtration through a bed of X1 and X2 were examined. These features are necessary to identify the impact of the filter material to the flowing water. Raw water was used as a model water prepared as follows: 120 liters of tap water prepared $1 \mathrm{~g}$ fed of the sulfate (VI), ammonium iron (II) $0.02 \mathrm{~g}$ sulfate (VI) manganese and $3 \mathrm{~g}$ enriched broth. Measurement of $\mathrm{pH}$ $(\mathrm{pH})$ were made using a $\mathrm{pH}$ meter CX-315's ELMETRON, and the measured conductivity probe YSI Professional Plus. Determination of COD-Mn was made by using manganate (VII) solution in accordance with PN/C-04578.02.

\section{RESULTS AND DISCUSSION}

The test was carried out with two natural porous filter beds. They were called X1 and X2 . Tested masses vary in color and graining:

- Mass X1 - black and fine-grained,

- Mass X2 - light brown and coarse grained. 
The Table 2 provide for both masses bulk density values, the results of sieve analysis or values calculated from the formula 1 and 2 , the equivalent diameter of the grains calculated from the formula 3, the coefficients of uniformity (formula 4), and porosity values of both materials calculated with two methods (Formula 5 and 6). In contrast, Figure 2 shows the sieving curves plotted for both analyzed filter materials.

Analyzing the calculated parameters of the filter materials there can be concluded that the $\mathrm{X} 1$ mass has a smaller equivalent diameter, resulting in a lower porosity of about $9-10 \%$, as compared to the weight of $\mathrm{X} 2$, which has much larger equivalent diameter of grains. Chmielowski and Wałęga research has shown that increasing the diameter of the particle size of the filtration bed extends the arrangement of the bed [Chmielowski, Wałęga 2011]. X2 mass should have a longer time to arrangement, compared to mass X1.

There was calculated diameters of the sieve mesh for the X1 mass which allows for separation of $10 \%$ of the filter material based on the above graph. The diameter was $-d_{10}=1,25 \mathrm{~mm}$. The diameter of the sieve mesh which stops $60 \%$ of the filter material was also established. That diameter was $\mathrm{d}_{60}=3,45 \mathrm{~mm}$. For the X2 mass the diameter of the sieve mesh which separates $10 \%$ of the filter material was $d_{10}=2,15 \mathrm{~mm}$. And the diameter of the sieve mesh which stops $60 \%$ of the filter material was $d_{60}=5,8 \mathrm{~mm}$. The diameter of the smallest particle filter bed was $d_{\min }=1 \mathrm{~mm}$, while the largest grain $\mathrm{d}_{\max }=10 \mathrm{~mm}$.

The Table 3 presents results of the $\mathrm{pH}$ in the raw water and filtered water through a X1 and X2 bed. The values of water $\mathrm{pH}$ after filtration are within $7.21-7.52$ in the case of the X1 mass, while for X2 filter bed $\mathrm{pH}$ was about 7.17 - 7.62. Raw water has a greater $\mathrm{pH}$ after the first week filtration than filtrated water through both masses. In the next test cycle the $\mathrm{pH}$ value was greater after filtration than the raw water in both cases.

Most of filter beds containing natural zeolites or aluminum silicates cause a slight increase in the $\mathrm{pH}$ of the water after filtration [Skoczko et al. 2015]. The reason is the chemical composition of minerals, which includes, inter alia, sodium, potassium, magnesium, calcium, barium, strontium forming reaction with water flowing alkaline hydroxides. Skoczko with the team [Skoczko et al. 2015] investigated filter beds containing natural materials such as silica sand, amorphous sand, silicates, etc. and in most cases water after filtration had a greater $\mathrm{pH}$. The analyzed masses X1 and $\mathrm{X} 2$ as a natural deposits also increase the $\mathrm{pH}$ of filtered water to slightly alkaline $\mathrm{pH}$ level (Figure 3). The $\mathrm{pH}$ may reach approx. 9.0 with the inclusion of an additional aeration, after applying filtration through X1 and X2 beds. Such phenomena may assist further removal of the manganese [Skoczko 2011].

Table 2. Physical parameters of the filter masses $X_{1}$ and $X_{2}$

\begin{tabular}{|l|c|c|}
\hline \multicolumn{1}{|c|}{ Parametr } & Masa X & ${\text { Masa } \mathrm{X}_{2}}_{1}$ \\
\hline Granulation & $1-10 \mathrm{~mm}$ & $1-10 \mathrm{~mm}$ \\
\hline Bulk density & $0.921 \mathrm{~kg} / \mathrm{dm}^{3}$ & $0.900 \mathrm{~kg} / \mathrm{m}^{3}$ \\
\hline Total sifting & $1.22 \rightarrow 38.89 \rightarrow 82.22 \rightarrow 98.11 \rightarrow 100[\%]$ & $0.8 \rightarrow 9.6 \rightarrow 19.8 \rightarrow 81.4 \rightarrow 100[\%]$ \\
\hline Equivalent diameter & $4.68 \mathrm{~mm}$ & $7.01 \mathrm{~mm}$ \\
\hline Coefficient of uniformity & $2.76 \mathrm{~mm}$ & $2.70 \mathrm{~mm}$ \\
\hline The porosity of the bed & & $65 \%$ \\
I method & $56 \%$ & $64 \%$ \\
II method & $55 \%$ & \\
\hline
\end{tabular}

Table 3. The $\mathrm{pH}$ of the water before and after filtration for a bed X1 and X2

\begin{tabular}{|c|c|c|c|}
\hline \multicolumn{2}{|c|}{$\mathrm{pH}$} & $\mathrm{X}_{1}$ & $\mathrm{X}_{2}$ \\
\hline Time of experiments [weeks] & Raw water & 7.52 & 7.44 \\
\hline 1 & 7.60 & 7.21 & 7.25 \\
\hline 2 & 6.85 & 7.29 & 7.17 \\
\hline 3 & 7.06 & 7.58 & 7.62 \\
\hline 4 & 7.40 & 7.47 & 7.60 \\
\hline 5 & 7.01 & & \\
\hline
\end{tabular}




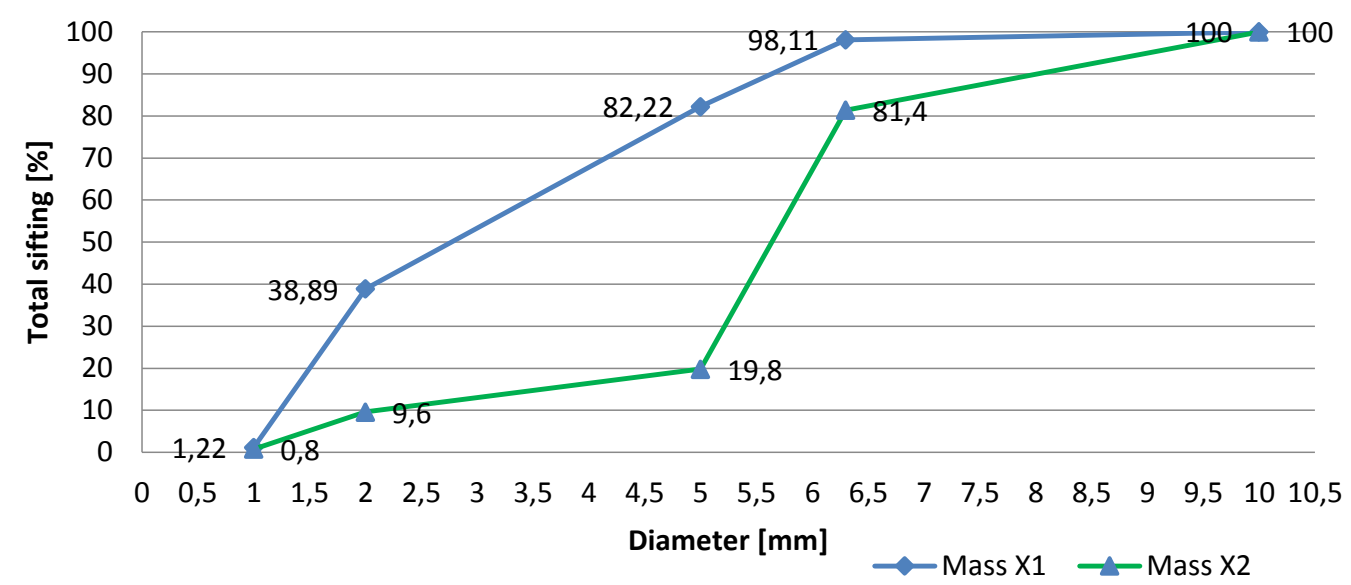

Figure 2. Graph showing the sieving curves for filter beds $\mathrm{X} 1$ and $\mathrm{X} 2$

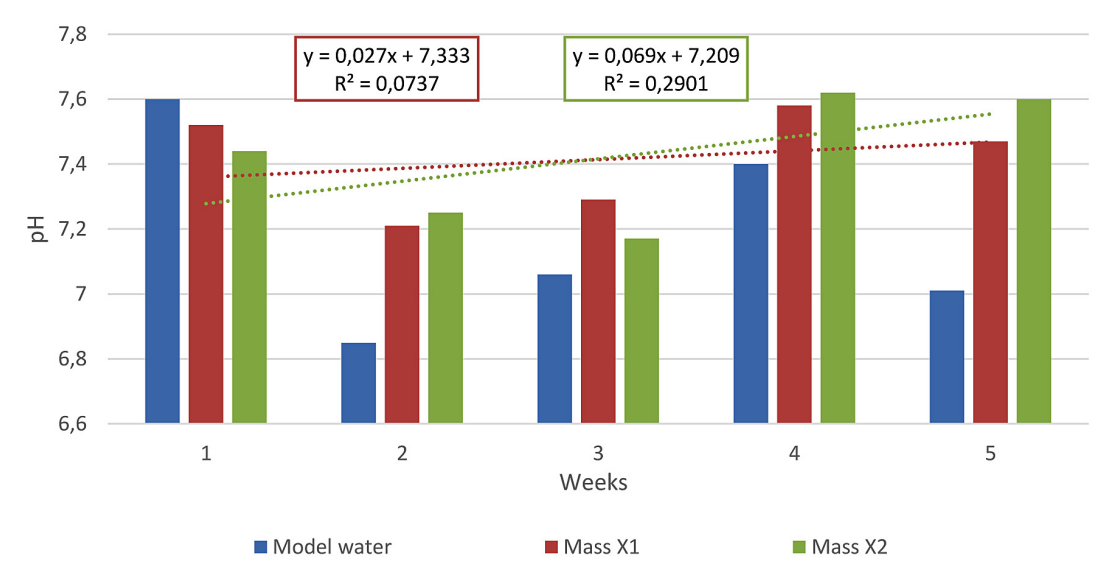

Figure 3. $\mathrm{PH}$ of the water before and after filtration through $\mathrm{X} 1$ and $\mathrm{X} 2$ bed

The Table 4 and the Figure 4 present data of the conductivity values for $\mathrm{X} 1$ mass. They ranged between 396 to $492.1 \mathrm{mS} / \mathrm{cm}$. The largest decrease in conductivity compared to the raw water occurred after the first week of research and amounted to $64.6 \mu \mathrm{S} / \mathrm{cm}$. On the other hand, in the next few weeks of testing this decline was small and ranged between 0.6 $-19.7 \mu \mathrm{S} / \mathrm{cm}$. The value of conductivity ranged from 408.5 to $497.4 \mu \mathrm{S} / \mathrm{cm}$ in the case of X2 filter bed. The largest decrease in conductivity as compared to the raw water followed as with the mass $\mathrm{X} 1$.
Figure 4 shows the decrease of conductivity which is considerable in the whole tests cycle. That phenomena can be caused by a decrease in mineralization. The reason for reducing the level of mineralization processes may be precipitation of mineral substances in the pores, especially in the presence of particulate material, wherein the contact surface grains and the solution is high.

Table 5 and Figure 5 present the results of the COD-Mn removal by X1 and X2 beds in the complete filtration cycle. The COD-Mn in the tested water was from 9.8 to $15 \mathrm{mg} / \mathrm{dm}^{3}$ for the mass X1. The lowest value amounted after the first week

Table 4. Value of conductivity in the water before and after filtration through X1 and X2 beds

\begin{tabular}{|c|c|c|c|}
\hline \multicolumn{4}{|c|}{ Conductivity $[\mu \mathrm{S} / \mathrm{cm}]$} \\
\hline $\begin{array}{c}\text { Time of experiments } \\
{[\text { weeks] }}\end{array}$ & Raw water & $\mathrm{X}_{1}$ & $\mathrm{X}_{2}$ \\
\hline 1 & 474.6 & 410.0 & 447.5 \\
\hline 2 & 501.2 & 492.1 & 497.4 \\
\hline 3 & 484.2 & 464.5 & 476.3 \\
\hline 4 & 491.0 & 490.4 & 490.9 \\
\hline 5 & 410.6 & 396.0 & 408.5 \\
\hline
\end{tabular}




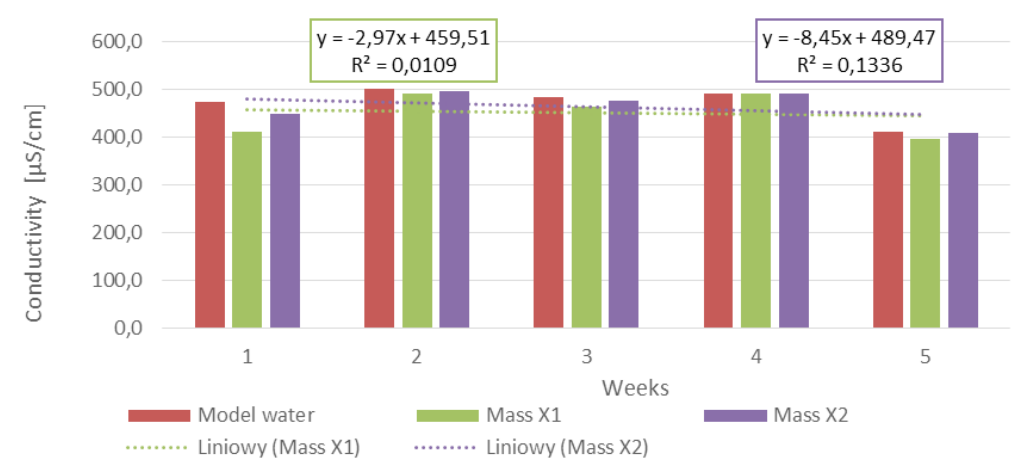

Figure 4. Changes of conductivity in water before and after filtration through $\mathrm{X} 1$ and $\mathrm{X} 2$ beds

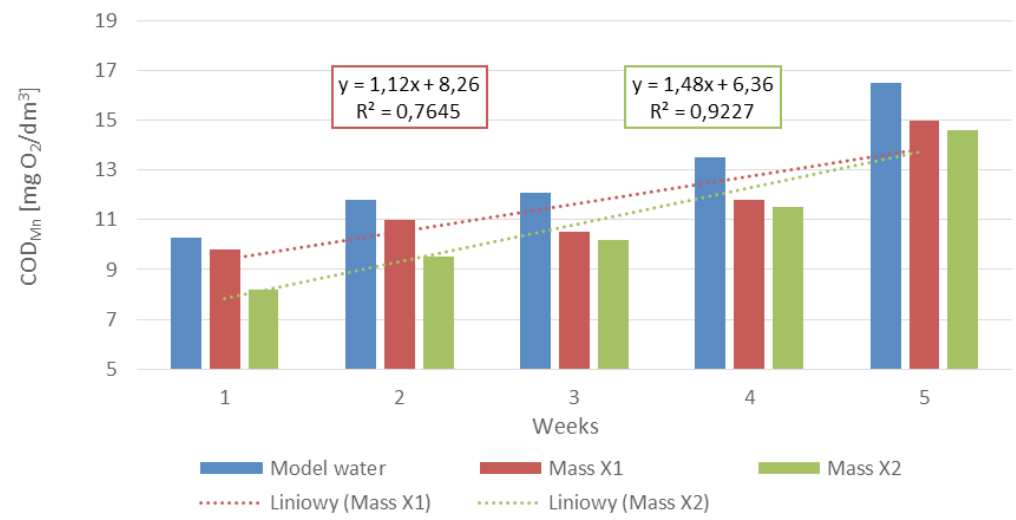

Figure 5. COD-Mn in the water before and after filtration through $\mathrm{X} 1$ and $\mathrm{X} 2$ beds

of testing about $9.8 \mathrm{O}_{2} \mathrm{mg} / \mathrm{dm}^{3}$ and the highest after the last week about $14.6 \mathrm{mg} / \mathrm{dm}^{3}$. The efficiency of COD-Mn removing during the entire filtration period was the smallest at the beginning and then it raised gradually. The best result came in the middle of the cycle, after the third week. It amounted to $13.2 \%$. The level of COD-Mn removal decreased in the last two weeks of tests and in the last week amounted to $9.1 \%$.

In the case of X2 mass COD-Mn was from 8.2 to $14.6 \mathrm{mg} / \mathrm{dm}^{3}$ in the tested water. The efficiency of its removal changed with time tests. It varied from $20.4 \%$ in the first week to $11.5 \%$ in the last.

The rising trend of COD-Mn concentration was noticed for both masses. All changes show the graph below (Figure 5). COD-Mn in the water before and after filtration increases with the test time. It indicates the presence of organic and inorganic substances in the water, which are easily oxidized, e.g. iron compounds, nitrogen. The reduction in COD after filtration process occurs by adsorption of impurities on the surface of the adsorbent (filter material).

A more effective material for removal of organic substances was X2. The concentration of COD-Mn decreased after filtration with $2.1 \mathrm{mg} /$ $\mathrm{dm}^{3}$. However, in the case of a X1 it was only 0.5 $\mathrm{m} / \mathrm{dm}^{3}$. In the last three weeks the level of CODMn efficiency removal significantly equalized. It was noticed that $\mathrm{X} 2$ bed proved to be slightly better. Wherein a difference of concentration decrease ranged from 0.2 to $0.6 \mathrm{mg} / \mathrm{dm}^{3}$ as compared with the X1 bed. However, the efficiency of organic and inorganic substances removal

Table 5. Values of COD-Mn in the water before and after filtration for X1 and X2 beds

\begin{tabular}{|c|c|c|c|c|c|}
\hline \multicolumn{4}{|c|}{ COD-Mn $\left[\mathrm{mg} \mathrm{O}_{2} / \mathrm{dm}^{3}\right]$} & \multirow{2}{*}{$\begin{array}{l}\text { Efficiency [\%] } \\
\text { for } \mathrm{X}_{1}\end{array}$} & \multirow{2}{*}{$\begin{array}{c}\text { Efficiency [\%] } \\
\text { for } \mathrm{X}_{2}\end{array}$} \\
\hline Time of experiments [weeks] & Raw water & $X_{1}$ & $\mathrm{X}_{2}$ & & \\
\hline 1 & 10.3 & 9.8 & 8.2 & 4.9 & 20.4 \\
\hline 2 & 11.8 & 11 & 9.5 & 6.8 & 19.5 \\
\hline 3 & 12.1 & 10.5 & 10.2 & 13.2 & 15.7 \\
\hline 4 & 13.5 & 11.8 & 11.5 & 12.6 & 14.8 \\
\hline 5 & 16.5 & 15 & 14.6 & 9.1 & 11.5 \\
\hline
\end{tabular}


expressed in general indicator of COD-Mn was not sufficient enough to use them as single beds. Compared to other filter materials, e.g. active carbon efficiency X1 and X2 masses were insignificant. Experiments of research group Luukkonen [Luukkonen et al. 2014] have shown that the removal of organic substances from distilled water using activated carbon can reach a level of about $50 \%$.

The efficiency of various pollutants removal from the contents of iron, manganese, nitrates until pesticides or PAHs should be checked with more detailed assessment of the analyzed filter beds. In addition, the analysis of chemical composition of the tested filtration materials ought to be the next step to identify the exact chemistry of individual water components' removal.

\section{CONCLUSIONS}

1. The largest sieve percentage of different fractions in the $\mathrm{X} 1$ bed is the fraction of $5 \mathrm{~mm}$ $(43.33 \%)$, while in the $\mathrm{X} 2$ - the fraction of $6,3 \mathrm{~mm}(61.6 \%)$.

2. The porosity of the X1 mass was $55-56 \%$, and of the X2-64-65\%.

3. Coefficient of uniformity for the X1 material was $2.76 \mathrm{~mm}$ and for the $X_{2}-2.7 \mathrm{~mm}$. The value of $\mathrm{WR}<5$ indicates evenly grained beds.

4. Satisfactory reduction of COD was not obtained for any of the tested filter beds. Mass X2 slightly better adsorbed organic substances. Both tested beds have not any possibility for removing organic matter from water. A slight decrease may cause the sorption of organic compounds suspensions with precipitating $\mathrm{Fe}(\mathrm{OH})_{3}$.

5. It was found that investigated filter masses significantly increase the $\mathrm{pH}$ of filtered water, which is due to its chemical composition.

\section{REFERENCES}

1. Çeçen F., Aktaşö. 2011. Activated carbon for water and wastewater treatment: integration of adsorption and biological treatment. Wiley-VCH, Weinheim.

2. Chmielowski K., Wałęga A. 2011. Preliminary examination of the stability of the removal of organic matter in the filter columns filled with sand and gravel. Science Nature Technologies 5, \#78. [in Polish]
3. Jeż-Walkowiak J. 2000. Characteristic of oxidative filter materials for manganese removal from groundwater, Proceedings of 4th International Conference on Water Supply and Water Quality, Krakow, Poland, 263-272.

4. Jeż-Walkowiak J. 2013. Requirements for materials filter. Economics and the Environment, 2(45), 70-80. [in Polish]

5. Jeż-Walkowiak J., Dymaczewski Z., Sozański M. 2011. Technological parameters of the filtration process hasty groundwater deposits of oxidation and chemically inactive, Journal of Ecological Engineering, 26, 112-121. [in Polish]

6. Kaleta J. 2005. Evaluation of usability of selected adsorbents for removing of organic pollutants from water, Monografie Komitetu Inżynierii Środowiska PAN, t. 32, Lublin, 179-186.

7. Kaleta J., Papciak D., Puszkarewicz A. 2009. Natural and modified minerals in the treatment of groundwater. Gaz, Woda i Technika Sanitarna, 25, 51-63. [in Polish]

8. Kowal A. L., Świderska-Bróż M. 2009, Water treatment. PWN. Warszawa. [in Polish]

9. Luukkonen T., Tolonen E.T., Runtti H., Pellinen J., Hu T. Rämöc J. 2014, Removal of total organic carbon(TOC) residues from power plant make-up water by activated carbon, Journal of Water Process Engineering, 3, 46-52.

10. Nawrocki J. 2010. Water treatment. Physical, chemical and biological processes. Wydawnictwo Naukowe PWN, Warszawa. [in Polish]

11. Nawrocki J., Biłozor S. 2000. Water treatment, chemical and biological processes, PWN, Warszawa-Poznań. [in Polish]

12. Papciak D., Zamorska J., Kaleta J., Puszkarewicz A. 2009. Effect of manganese (II) on the time of biofilm formation and on the effectiveness of amonium nitrogen removal from water in biofiltration process. Polish Journal of Environmental Studies vol. 2:

13. Skoczko I. 2011. Project and implementation experience of boiler water treatment plant for ENERGO-TECH sp. z o.o. Annual Set the Environment Protection, 13, 1731-1742.

14. Skoczko I., Kisło A. 2014. Analysis of ecological activity of Podlasie province. Journal of Ecological Engineering. 15(1), 1-6.

15. Skoczko I., Piekutin J., Roszczenko A. 2015. Iron and manganese removal from groundwater

16. By filtration on selected masses, Annual Set the Environment Protection, 17, 1587-1608. [in Polish]

17. Weber Ł., Jeż-Walkowiak J. 2006. Types of filtration beds: Comparison of the effectiveness of the filtration process. Wodociągi - Kanalizacja. 11, 53-57. [in Polish] 